\title{
A (auto)avaliação das escolas: "virtudes" e "efeitos colaterais"
}

- Virgínio Sá*

\section{Resumo}

Ao longo das duas últimas décadas, em contextos sócio-políticos muito diversos, primeiro nos países centrais, depois nos países semi-periféricos e periféricos, a agenda avaliativa, nas suas diferentes configurações e domínios de incidência, tem vindo a assumir uma enorme centralidade. No caso de Portugal, as alterações recentes no quadro legislativo que enquadra as nossas escolas e os seus profissionais, com destaque para o novo estatuto da carreira docente do ensino não superior e para a "indexação" dos muito propalados contratos de autonomia à prévia existência de processos auto-avaliativos e de avaliação externa, catapultaram esta problemática para as primeiras páginas da agenda pública. As razões deste (súbito) interesse pelas questões da avaliação educacional em geral, e da avaliação institucional em particular, organizam-se em torno de uma pluralidade de eixos estruturadores filiados em lógicas e racionalidades em tensão, uns mais vinculados às preocupações com o controlo, outros mais sintonizados com uma agenda emancipatória.Neste texto pretende-se discutir algumas daquelas lógicas e racionalidades em tensão, articulando-as com a diversidade de agentes e de agendas que a avaliação pode servir. De modo mais específico, procura-se pôr em evidência alguns dos "efeitos colaterais" decorrentes de concepções e práticas avaliativas que ignoram, ou desprezam, a assunção da escola como "organização educativa complexa".

Palavras-chave: Avaliação institucional. Auto-avaliação. Avaliação externa. Qualidade.

\section{School (self)evaluation: "virtues" and "collateral efects" \\ Abstract}

Throughout the two last decades, in diverse social political contexts, firstly in central countries, later in the peripheral and the semi-peripherals countries, the assessment agenda, in its different configurations and domains of incidence, has come to assume an enormous centrality. In the case of Portugal, the recent alterations in the educational legislation that fits our schools and its professionals, with prominence for the new statute of the teaching career and for the "indexation" of the contracts of autonomy to the previous existence of internal and external evaluation processes, had raised this problematic on the first pages of the public agenda. The reasons of

\footnotetext{
* Doutor em Educação; Professor Auxiliar do Instituto de Educação e Psicologia da Universidade Minho, Portugal. E-mail:virsa@iep.uminho.pt
} 
this interest for the questions of the educational evaluation in general, and the institutional evaluation in particular, organize around a plurality of structuring axles originated in logics and rationalities in tension, some more tied with the concerns with the control, others more syntonized with an emancipatory agenda. In this text we intend to discuss some of those logics and rationalities in tension, articulating them with the diversity of agents and agendas that the evaluation can serve. In a more specific way, we essay to put in evidence some of the "collateral effects" emerging from assessment conceptions and practices that ignore, or disdain, the assumption of the school as a "complex educational organization".

Keywords: Institutional evaluation. Self-evaluation. External-evaluation. Quality.

\section{La (auto)evaluación de las escuelas: "virtudes" $y$ "efectos colaterales" Resumen}

A través de las dos décadas pasadas, en contextos políticos y sociales diversos, primero en los países centrales, después en los países periféricos y semi-periféricos, la agenda evaluativa, en sus diversos configuraciones y dominios de incidencia, ha venido asumir un interés enorme. En el caso de Portugal, los cambios recientes en el cuadro legislativo que regula nuestras escuelas y a sus profesionales, con prominencia para el nuevo estatuto de la enseñanza y de la educación no superior y para la "indexación" de los contratos de la autonomía a los resultados de la auto-evaluación y de la evaluación externa, proyectaron este tema para las primeras páginas de la agenda pública. Las razones de este interés por las cuestiones de la evaluación educativa en general y de la evaluación institucional en particular, se organizan alrededor de una pluralidad de ejes estructuradores, filiados en lógicas y racionalidades en tensión, unos más articulados con las preocupaciones con el control, otros más en sintonía con una agenda emancipatória. En este texto se piensa discutir algunas de esas lógicas y racionalidades en tensión, las articulando con la diversidad de agentes y agendas que la evaluación pueda servir. En una manera más específica, se mira poner en evidencia algunos de los "efectos colaterales" que se desarrollan en consecuencia de las concepciones y prácticas de evaluación que no hacen caso, o desdeñan, de la escuela como "organización educativa compleja". Palabras clave: Evaluación institucional. Auto-evaluación. Evaluación externa. Calidad.

\section{A dimensão holística e integradora da avaliação institucional}

Importa começar por esclarecer que neste texto se toma como objecto de análise e reflexão a avaliação institucional das escolas, com destaque particular para a autoavaliação. Considerando a pluralidade de modalidades e sentidos que a avaliação pode assumir, julgamos conveniente começar por clarificar em que acepção específica se 
toma aqui a avaliação institucional. Na linha de outros autores, consideramos que uma possível démarche metodológica para a dilucidação deste conceito pode passar por salientar primeiro o negativo da imagem, ou seja, explicitar antes o que não é avaliação institucional. Assim, e mobilizando as palavras de Dias Sobrinho (2000, p. 103), começamos por esclarecer que "não se trata de avaliar isoladamente conhecimentos, docentes individuais, estudantes como categoria separada, os meios sem relação com os fins, nem se trata de tentar somar essas análises fragmentárias para construir um 'puzzle'"

Fica, portanto, claro que a avaliação institucional de uma escola não pode ser tomada como equivalente ao produto da soma das várias avaliações insularizadas, realizadas segundo agendas e agentes desconectados. Pelo contrário, a avaliação, porque é institucional, terá de ser, necessariamente, holística e integradora. 0 primeiro requisito põe em evidência que é a escola enquanto totalidade que é o objecto de avaliação; o segundo requisito complementa o primeiro conferindo agora destaque à necessidade de articulação das várias démarches avaliativas e à sua subordinação ao documento que é suposto conferir rumo e identidade à escola- o seu Projecto Educativo. Como afirma Dias Sobrinho (1995, p. 39): "A qualidade não está nos fragmentos, na separação, mas sim na integração, nas relações de conjunto." Em coerência com este pressuposto, Dias Sobrinho (2000, p. 103) define a avaliação institucional nos seguintes termos:

A avaliação institucional é uma construção colectiva de questionamentos, é uma resposta ao desejo de ruptura das inércias, é um pôr em movimento um conjunto articulado de estudos, análises, reflexões e juízos de valor que tenham alguma força de transformação qualitativa da instituição e do seu contexto, através da melhora dos seus processos e das relações psicossociais. ${ }^{1}$

Através desta conceptualização, Dias Sobrinho procura superar os reducionismos frequentemente associados aos processos avaliativos, reflectindo na própria definição a densidade e complexidade das organizações educativas. Simultaneamente, desloca o foco das obsessões métricas ("quantofrenia") para a produção de "reflexões e de juízos de valor", pondo em evidência a natureza política do processo de avaliar. Ao subordinar a agenda avaliativa às preocupações com a "melhoria dos processos e da relações psicossociais", este autor desvincula ainda a avaliação institucional da distribuição de "punições e recompensas", desdramatizando, também por essa via, um processo que, para ser assumido com verdade, não pode ser vivido como uma espada de Dámocles permanentemente apontada à cabeça dos avaliados/avaliadores. Quando assim é, o que não é raro, o processo de avaliação transforma-se num jogo "do gato e do rato" onde, por cada tentativa de controlo, se podem mobilizar "inúmeros dispositivos de oposição, de subversão ou de fuga" (VENTURA, 2006, p. 156). No mesmo sentido se pronuncia Santos Guerra (2002) ao

1 Trinidad Requena (1995, p. 7 apud DIAS SOBRINHO, 1995, p. 95- 96), insere-se nesta mesma linha de problematização ao definir avaliação institucional como "um processo descritivo, sistemático e rigoroso, com enfoque global ou holistico, permanente, integrado à actividade educativa da instituição, reflexivo, compreensivo, que propicia a melhora da instituição educativa." 
considerar que um processo avaliativo que não é assumido pelos actores educativos, particularmente pelos docentes, habitualmente gera resistências, promove teatralizações e produz imagens distorcidas que se revelam inúteis. De facto, afirma este autor, se "os professores rejeitam o processo, jogam à defesa, artificializam o comportamento, negam a evidência, então a avaliação será uma perda de tempo." (SANTOS GUERRA, 2002, p. 51).

Considerando que as escolas são "organizações sociais complexas" (AFONSO, A. J., 2003; SANTOS GUERRA, 2002)², a sua avaliação institucional (ou qualquer outro tipo de avaliação) não pode ser reduzida a uns quantos procedimentos técnicos, ainda que sofisticados, orientados por obsessões métricas, por mais imperativas que estas se apresentem. Na verdade, como denuncia Lima (1997, p. 55) reportando-se ao ensino superior, a ênfase no mensurável induz um paradigma de "educação contábil", subordinada a uma agenda gerencialista e tecnocrática, que, nas palavras deste autor, revaloriza "concepções mecanicistas das organizações e da administração educativas", ao mesmo tempo que despreza, ou secundariza, "os processos e os resultados mais difíceis de contabilizar". Neste cenário, afirma ainda Lima (1997, p. 55, grifo nosso): "Parece claro que à avaliação virá a ser conferido o estatuto de fiel da balança, de selo de garantia ou de certificado de qualidade, procurando-se desta forma repor a confiança social no sistema, entretanto perdida ou abalada e cobrindo défices de legitimidade." Esta afirmação de Lima constitui uma oportuna advertência em relação aos discursos voluntaristas que sacralizam a avaliação e que julgam ver nesta a panaceia para todos os males que afectam a educação. Contudo, se a avaliação não constitui o amuleto que vai esconjurar a crise da educação e da escola, também não deve ser perspectivada como a boceta de Pandora a quem todas as doenças podem ser imputadas. Na verdade, a (auto)avaliação das escolas pode servir diferentes agentes e diferentes agendas e ancorar-se em racionalidades plurais e, eventualmente, contraditórias. No ponto seguinte dá-se estaque à problematização da convivência tensa entre diferentes quadros de inteligibilidade e lógicas de acção dos processos avaliativos.

\section{A (auto)avaliação das escolas: entre o "olho normalizador” e as aspirações emancipatórias}

Na panóplia de "razões" susceptíveis de serem convocadas para conferir inteligibilidade ao (súbito) interesse pela avaliação das escolas é possível identificar lógicas e agendas relativamente diversas e, nalguns casos, filiando-se em argumentos legitimadores em clara tensão, umas mais centrados nas preocupações com a conformidade burocrático-formal, outras mais coerentes com uma concepção das escolas como comunidades educativas, dotadas de autonomia e orientadas para a promoção de um projecto crítico e democratizante.

2 Como observa Santos Guerra (2002, p. 11) : "Avaliar escolas com rigor implica conhecer a especial natureza e configuração que elas têm, enquanto instituições enraizadas numa determinada sociedade: a sua heteronomia, as suas competentes nomotéticas, os seus fins ambíguos, a sua débil articulação, a sua problemática tecnologia. Por outro lado é imprescindivel ter em conta o caráter único, irrepetivel, dinâmico, cheio de valores e imprescindivel de cada escola." 
Num esforço de inventariação dos factores subjacentes à "pressão para a avaliação das escolas", Azevedo (2007) discrimina doze "questões" que arruma em três categorias: "políticas, sociais e económicas". Nesta listagem incluem-se a descentralização e a autonomia e a correlativa prestação de contas; a reivindicação de informação por parte do consumidor como condição para práticas de escolha informadas; a assunção da escola como "unidade crítica" associada aos estudos sobre o "efeito-estabelecimento"; as preocupações com a (baixa) "produtividade" das escolas em contraste com os (supostos) elevados investimentos públicos; o "insucesso" da escola em assegurar o sucesso de todos; a avaliação entendida como "estratégia de marketing"; o (suposto) desfasamento entre as exigências do "mundo do trabalho" e a oferta educativa das escolas; a crise de confiança na escola decorrente, nomeadamente, da sua "massificação"; a avaliação (séria) como um contraponto às formas "preguiçosas" de avaliação (ex. os rankings); as pressões internacionais e a avaliação como alternativa à "verificação da conformidade"; a avaliação como factor de melhoria e como condição para o desenvolvimento de "comunidades profissionais" (AZEVEDO, 2007, p. 21-22).

As "razões" aqui elencadas são passiveis de articulação com as respostas que Costa e Ventura (2005) dão ao "para quem e para quê?" da avaliação das instituições educativas. Na sintese destes autores, os processos de avaliação institucional podem estar ao serviço de três grandes finalidades: o mercado, o relatório e a melhoria. Cada uma destas imagens da avaliação diferencia-se em relação aos destinatários servidos pela avaliação, quanto aos objectivos perseguidos, no que concerne aos conteúdos privilegiados, em relação aos procedimentos adoptados e à concepção de escola que lhes está subjacente. Assim, por exemplo, relativamente à concepção de escola, enquanto a avaliação para o mercado surge associada a uma concepção de escola como empresa educativa, em que a grande finalidade é captar clientes, já para avaliação que está ao serviço da produção do Relatório, a concepção de escola subjacente é a de uma burocracia ritualizada, em que a avaliação visa sobretudo verificar a conformidade legal, cumprindo um ritual de fachada. Por seu lado, se a avaliação se orienta para a melhoria, a concepção de escola subjacente é a de uma comunidade de aprendizagem, entendida esta como "um processo democrático, de construção colectiva, com base no desenvolvimento das capacidades profissionais dos seus membros" (COSTA; VENTURA, 2005, p. 4).

Cada uma das cinco dimensões de análise acima discriminadas mantém uma relação de coerência interna com as demais. As respostas que damos às interrogações para quem se avalia, para que se avalia, o que se avalia e o como se avalia subsumem uma determinada concepção da escola como organização. Como afirma Lima (2002, p. 17): "a avaliação educacional de alunos, escolas, ou departamentos, entre outros elementos, realiza-se necessariamente por referência, implícita ou explícita, a concepções, imagens ou representações de organização escolar". As diferentes concepções de escola subjacentes aos vários modelos de avaliação transportam consigo formas distintas de entender o significado das estruturas organizacionais, de pensar os objectivos, de problematizar as tecnologias, de equacionar as 
relações de poder, de reconhecer a interacção ambiental e de interpretar o sentido da liderança. Há, portanto, vantagem em que as diferentes concepções e imagens organizacionais subsumidas nos modelos de avaliação das escolas sejam explicitadas pois esta démarche poderá constituir a via que permitirá desvelar e denunciar as potenciais inconsistências e incongruências entre os valores efectivamente promovidos por determinados dispositivos de avaliação e aqueles que são invocados no âmbito da retórica discursiva que os sustenta. Desde logo cabe perguntar, por exemplo, se um modelo de avaliação que subsume uma concepção de escola à imagem da máquina pode, de modo congruente, invocar a agenda do desenvolvimento organizacional como modo de justificação.

0 que neste ponto se procura enfatizar é que a avaliação das escolas pode servir agentes e agendas muito diversos e que, ao contrário do que sustentam certos discursos normativos e laudatórios, não está na sua natureza servir uns ou outros. Por isso, como alerta Santos Guerra (2003, p. 13): "É muito importante saber a que valores serve e a que pessoas beneficia". Não se trata, portanto, de um mero processo técnico, mais ou menos sofisticado, de medição. Na mesma linha de análise se situa Dias Sobrinho $(2000$, p. 91) quando afirma: "as avaliações operam como instrumentos quase científicos, quase técnicos, sempre sociais e éticos de consolidação e denegação de valores." Reconhecer a natureza política da avaliação constitui um primeiro requisito para frenar certos ímpetos tecnocráticos e gerencialistas que animam determinadas versões do Estado avaliador. A atrelagem da avaliação à qualidade, sem se questionar as modalidades daquela nem os sentidos desta, facilita também uma instrumentalização da avaliação com a consequente despolitização da mesma. Por isso, no ponto seguinte, o foco será orientado para problematização daquela relação complexa e para o desvelar de alguns dos significados ocultos que a sua invocação pode abrigar.

\section{Avaliação e qualidade: as duas faces da mesma moeda?}

Se, como afirmamos na abertura deste texto, ao longo das últimas décadas, as preocupações com a avaliação das organizações educativas têm vindo a assumir uma grande centralidade, a demanda da qualidade não lhe fica atrás. ${ }^{3}$ Mariano Enguita (1997, p. 95), num texto sugestivamente intitulado "O discurso da qualidade e a qualidade do discurso", põe precisamente em evidência o carácter omnipresente e imperativo dessa demanda:

\footnotetext{
$3 \mathrm{Em}$ Portugal, um exemplo sugestivo da súbita obsessão pela qualidade pode encontrar-se nas propostas que os partidos politicos submeteram a sufrágio nas eleições legislativas de março de 2002.0 caso mais paradigmático é o do partido socialista (PS). 0 ponto 4 do capitulo IV do seu "programa de governo", secção onde se abordam as propostas desta força partidária para o sector da educação, tem por título "Educação de Qualidade, Educação para Todos". Nas cerca de oito páginas (pp. 67-74) dedicadas à explanação dos principios e das medidas propostas para fazer de Portugal "Dos melhores entre os melhores"no ensino não superior, o termo "qualidade"é reiteradamente mobilizado nas mais diversas combinações. "Educação de qualidade"; "ganhos de qualidade"; "contratos de qualidade"; "equipamentos com qualidade"; "Administração educativa ao serviço da qualidade"constituem algumas das muitas expressões em que o conceito é utilizado. Só nas referidas oito páginas o termo "qualidade"é convocado mais de 30 vezes e numa delas atinge a dezena de referências.
} 
Se existe hoje uma palavra em moda no mundo da educação, essa palavra é, sem dúvida, "qualidade". Desde as declarações dos organismos internacionais até às conversas de bar, passando pelas manifestações das autoridades educacionais, as organizações de professores, as centrais sindicais, as associações de pais, as organizações de alunos, os porta-vozes do empresariado e uma boa parte dos especialistas, todos coincidem em aceitar a qualidade da educação ou do ensino como objectivo prioritário ou como um dos muito poucos que merecem consideração. ${ }^{4}$

A qualidade, como a avaliação, parece, assim, ter-se transformado numa espécie de amuleto capaz de esconjurar a crise que recorrentemente se abate sobre a educação: bastará invocá-la (nas suas diferentes combinações) para que, como por magia, uma aura de bondade envolva as propostas que a invocam. Contudo, como adverte Gentili (1997, p. 115): "No campo educativo, o discurso da qualidade foi assumindo a fisionomia de uma nova retórica conservadora funcional e coerente com o feroz ataque que hoje sofrem os espaços públicos (democráticos ou potencialmente democráticos), entre eles a escola das maiorias." Gentilli, reportando-se ao "cenário político latino-americano", observa que, a partir de finais da década de oitenta, princípios da década de noventa do séc $X X$, a agenda da democratização cede progressivamente lugar ao discurso da qualidade, entendendo-se esta na sua versão mercantil, ou seja, subordinada às preocupações com a eficiência e a eficácia como condições para a adaptação às novas condições do mercado. Também Lima (1994), reportando-se à realidade portuguesa, identifica igualmente uma subordinação da agenda democratizadora ao imperativo da modernização, processo em Portugal marcado por algumas singularidades. Depois de reconhecer que "O fenômeno não é especificamente português", Lima (1994, p. 124) afirma:

0 que há, talvez, de específico no caso português é o tipo de ruptura com o discurso da democratização, fortemente enraizado na política educativa desde 1974 (e até mesmo antes), e a tentativa de articular aquele discurso com a ideologia da modernização. [...] o discurso da democratização não é completamente afastado, mas antes reconvertido e subordinado à ideologia da modernização e com ela compatibilizado.

Neste cenário, observa ainda Lima (1994, p. 128): "a ideologia e o discurso da qualidade estão bem patentes nas políticas educativas", verificando-se em diversos documentos enquadradores da educação e das escolas "a repetição, por vezes até à exaustão, da referida palavra." ${ }^{5}$ Ao contrário do que se passa no campo produtivo-

4 Mais adiante, o mesmo autor afirma: "Qualquer proposição relativa a conservar, melhorar ou mudar isto ou aquilo, não importa o que seja, deve explicar-se em termos de qualidade."(ENGUITA, 1997, p. 95).

5 Nestas circunstâncias, acrescenta de seguida Lima (1994, p. 128): "Bastará, então, falar em eficácia e em qualidade, mesmo sem a sua obtenção empírica, para alcançar aqueles propósitos." 
empresarial, o que os promotores do discurso da qualidade no campo educativo parecem ignorar é que a qualidade, ainda que reduzida à versão mercantil, tem um preço. Contudo, no domínio da educação, a retórica da qualidade surge frequentemente associada, e como factor compensatório, ao desinvestimento público nas escolas. De facto, como denuncia Lima (1994), a obsessão pela qualidade, e pelo seu controlo, não tem tido correspondência numa política de promoção efectiva da qualidade. Por isso, admite este autor, o discurso da qualidade pode afinal não passar de "retórica com propósitos de reposição da confiança no sistema e de legitimação institucional." (LIMA, 1994, p. 128).

Apesar do carácter quase obsessivo com que o termo "qualidade" é recorrentemente mobilizado nos mais diversos contextos, são raros os investimentos na clarificação do(s) sentido(s) que lhe podem estar subjacentes. Não se problematiza, portanto, "qualidade para quem?" ou, não menos importante, "qualidade segundo quem?" (OCDE, 1992). Tudo se passa como se o conceito de "qualidade" fosse univoco e consensual. Ora, como adverte Lima (1994, p. 127-128), a propósito da utilização igualmente acrítica do conceito de "eficácia", o conceito só deixa de ser problemático no "quadro de uma racionalidade à priori", de contrário, parafraseando ainda Lima, teríamos que admitir que não há uma mas várias qualidades, "tantas, possivelmente, quantos os modos de racionalidade em presença conflitual" (LIMA, 1994, p. 127-128). Também Gentili (1997, p. 172, grifo do autor) alerta para a polissemia deste conceito e, de modo concomitante, para a necessidade da sua devolução à esfera política:

0 significado da qualidade e, consequentemente, a definição dos instrumentos apropriados para avaliá-la, são espaços de poder e de conflito que não devem ser abandonados. [...] Devemos sustentar com decisão que não existe um critério universal de qualidade lainda que os intelectuais reconvertidos assim o pretendam!).

Não há, contudo, esclarecemos, nada de demoníaco no termo "qualidade". 0 que aqui se procura pôr a descoberto são os discursos hegemónicos que veiculam versões monolíticas (e mercadorizadas) de uma realidade que é por natureza plural. 0 discurso da qualidade pode ser, mas não tem de ser, excludente. Como expressivamente observa Almerindo Janela Afonso (2003, p. 51):

Se considerarmos que a qualidade da educação escolar não se consubstancia apenas na sua qualidade científica e pedagógica, mas também, e em simultâneo, na sua qualidade democrática, não podemos deixar de exigir que a avaliação das escolas públicas se estruture através de procedimentos mais complexos, diversificados e muito distintos daqueles que se têm baseado os exames externos estandardizados ou padronizados. 
Esta citação, ao pôr em evidência a natureza pluridimensional da qualidade, abre espaço para a consideração da multiplicidade de critérios e de lógicas de acção que é imperativo considerar na avaliação da prestação do serviço educativo. Esses critérios apresentam-se muitas vezes em tensão, sendo, por isso, dificeis de traduzir em agendas coerentes e dificeis de captar em simultâneo por um determinado dispositivo de avaliação. Ora os diferentes "programas de avaliação" não são neutros, eles reflectem um conjunto de opções e, como afirma Natércio Afonso (2002, p. 52), "os juízos que se produzem dependem dos padrões de referência que se adoptam e dos indicadores que os operacionalizam". Por essa razão, e como afirma o mesmo autor:

É provável que o desempenho organizacional e a 'qualidade' de uma escola onde predominam preocupações com a equidade e a coesão social não sejam adequadamente reconhecidos por um programa de avaliação que privilegia, ao nível da definição dos padrões de referência, a liberdade de escoIha, a eficiência e a produtividade. (AFONSO, N., 2002, p. 54).

Na verdade, e como sustenta Azevedo (2007, p. 16), "as criações sociais são sempre muito mais complexas do que os instrumentos de que dispomos para as avaliar", de onde resulta que os dispositivos e os juízos avaliativos serão sempre selectivos. Contudo, o reconhecimento desta parcialidade e subjectividade não significa excluir a possibilidade e necessidade de avaliação das escolas e, menos ainda, sucumbir a qualquer deriva positivista. Implica antes reconhecer, mais uma vez, a politicidade (e complexidade) de qualquer processo avaliativo e, por consequência, a necessidade de (re)inscrever o debate sobre a avaliabilidade da escola na arena mais ampla dos processos de reconfiguração do papel do Estado e de redefinição dos mecanismos de regulação.

Como referimos antes, na linha de outros autores, a avaliação das escolas pode estar ao serviço do mercado, do relatório e da melhoria. Também deixamos entender que a avaliação se pode subordinar mais a uma agenda de modernização ou de democratização. Importa reflectir sobre as circunstâncias e as condições em que a avaliação pode, mais plausivelmente, servir cada uma daquelas agendas e, em particular, em que circunstância pode a avaliação "alimentar a lucidez" (AZEVEDO, 2007). No ponto seguinte daremos particular atenção à discussão destas (im)possibilidades. A análise centrar-se-á sobretudo no confronto entre a auto-avaliação e a avaliação externa, procurando explorar as respectivas "forças" e as "fraquezas".

\section{Auto-avaliação e avaliação externa: forças e fraquezas}

Santos Guerra (2002, p. 15-17), ao discutir a "origem da iniciativa" da avaliação, hierarquiza um conjunto de possibilidades, que estrutura gradativamente em função do menor ao maior "poder educativo da avaliação". Nessa "sequência de possibilidades" este autor discrimina quatro tipos: i) avaliação externa com caráter de imposição; ii) inici- 
ativa externa com carócter de proposta; iii) iniciativa interna sem facilitadores externos; iv) e iniciativa interna com facilitadores externos. ${ }^{6}$ Para este autor, o último tipo (iniciativa interna com facilitadores externos) constitui a modalidade mais rica pois, "Se a iniciativa for da própria comunidade e se, para a levar a acabo, se puder contar com facilitadores externos (chamemo-lhe avaliadores, se quisermos), existem muitas garantias de levar o processo a bom termo" (SANTOS-GUERRA, 2002, p. 17).

Costa e Ventura (2005, p. 151) sustentam igualmente que: "Se o objectivo de determinada avaliação consistir na melhoria efectiva do funcionamento da organização, então, a auto-avaliação surge como uma modalidade fundamental". Para fundamentar esta posição, Costa (2007, p. 231) convoca Stufflebeam (2001), autor que defende que "os indivíduos têm mais probabilidades de compreender, valorizar e usar os resultados de uma avaliação se estiverem significativamente envolvidos em todo esse processo." Contudo, denuncia Costa (2007, p. 233), "há condições básicas para o desenvolvimento da avaliação das escolas públicas portuguesas que não estão institucionalizadas." Nessas "condições básicas" Costa inclui a autonomia contratualizada e a assessoria qualificada. Em relação à primeira, este autor interroga com toda a propriedade: "se não há autonomia das escolas, o que é que estas estão a avaliar? As decisões escolares ou as directrizes e as indicações que existem sobre as escolas?" (COSTA, 2007, p. 233). Quanto à segunda (assessoria qualificada) ${ }^{7}$, Costa defende que ela tanto pode ser interna como externa e, neste último caso, admite que possa ser assegurada por outras escolas no quadro do que denomina de "colaboração inter-institucional."8

Se a auto-avaliação pode surgir como, aparentemente, mais congruente com uma agenda orientada para a melhoria na prestação do serviço educativo, desde logo porque geradora de um maior empenhamento na promoção e execução das "recomendações" decorrentes do processo avaliativo, ela não está isenta de "toxinas" que podem adulterar a referida agenda centrada na melhoria. ${ }^{9} \mathrm{Na}$ verdade, e ao contrário

6 Esta tipologia, como esclarece Santos Guerra (2002), não pretende ser exaustiva. Na verdade, também poderemos considerar o tipo avaliação interna com caráter impositivo). No quadro normativo que regula o sistema de avaliação da educação e do ensino não superior (Lei n 31/20 02, de 20 de dezembro), esclarece-se que "A avaliação estrutura-se com base na autoavaliação a realizar em cada escola ou agrupamento de escolas, e na avaliação externa."(art ${ }^{\circ} 5^{\circ}$ ) e logo de seguida determinase que "A auto-avaliação tem caráter obrigatório, desenvolve-se em permanência, conta com o apoio da administração"(art ${ }^{\circ}$ $6^{\circ}$ ) e deve assentar nos termos de análise definidos pela própria administração. Trata-se de mais um caso em que as escolas "são obrigadas a escolher livremente"(CANÁ RIO; ALVES; ROLO, 2001).

7 A assessoria qualificada, quando exercida por entidades externas, tem alguns pontos de convergência com os "facilitadores externos" a que se reporta Santos Guerra.

8 A este propósito Costa cita a seguinte (e interessante) afirmação de Michael Fullan (2001 apud COSTA, 2007, p. 234-235): "É uma das maiores ironias da vida: as escolas têm por finalidade ensinar a aprender, no entanto, são péssimas no que se refere a aprender umas com as outras. Se um dia descobrirem como isso se faz terão o futuro assegurado."

9 Graça Simões (2007, p. 44), num breve texto onde expõe um projeto de investigação na área da auto-avaliação das escolas, alerta-nos de forma particularmente acutilante para os potenciais riscos do "auto": "Sabe-se como o "auto" pode ser aprisionante e "dominador das almas", com um substituir do controlo direto por uma "sujeição produtiva" no sentido foucaultiano (CLARKE; NEWMAN, 1997, p. 30). Sabe-se como o crescente "individualismo concreto", nascido de um enfraquecimento do principio da autoridade (VANDANBERGHE, 2001, p. 115), pressupõe mais liberdade nas relações de pertença, mas também mais responsabilidade pelas opções. Está demonstrado como esta espiral do controlo "do exterior dos dispositivos para o interior das pessoas" (MANGEZ, 2001, p. 91) pode causar sofrimento e solidões (CORREIA; MATOS, 2001) e, em combinação com as pressões de eficácia e de eficiência, levar a uma esquizofrenia da performatividade, em que os sujeitos vivem as suas vidas como "empresas do seu eu" (BALL, 2002)."Esclarece logo de seguida esta autora que "todas estas formulações podem ter os seus contrários" e, portanto, nada há de determinista e de inevitável nestes riscos potenciais. 
do que sustentam certas análises mais apologéticas, não há uma relação necessária entre auto-avaliação e juízos avaliativos mais rigorosos e verdadeiros. Se os avaliadores internos beneficiam de uma maior familiaridade com o contexto em análise e de uma maior sintonia com a cultura da organização, por outro lado, poderão ser mais vulneráveis em relação a certas pressões locais e não disporem do distanciamento e da visão em perspectiva necessários à produção de leituras mais isentas. Por isso, diversos autores consideram que há vantagem em que os processos de auto-avaliação sejam complementados e cruzados com olhares externos que, não sendo necessariamente mais objectivos, poderão contudo "interpelar" o olhar interno. ${ }^{10}$ Nesta linha de análise, como defende Azevedo (2007, p. 77): "0 modo mais coerente e eficaz de fazer avaliação institucional está na relação sinérgica entre auto-avaliação e a avaliação externa, entendida esta como suporte e interpelação à auto-avaliação."

\section{Avaliação, pressões performativas e fabricações}

A associação da avaliação institucional às diversas agendas (mercado, relatório ou melhoria) não depende só, ou não depende apenas, do promotor ou do autor da avaliação, mas sobretudo do contexto macro estrutural em que a avaliação se desenvolve e dos usos (e abusos) de que possa ser objecto. Santos Guerra (2002, p. 287-288), por exemplo, sinaliza dez "perigos" que "espreitam" a avaliação das escolas, ameaças que podem afectar tanto a auto-avaliação quanto a avaliação externa. A abrir o leque dos abusos que se podem praticar com a avaliação das instituições educativas, Santos Guerra (2002, p. 287-288) refere o perigo de "Transformar a avaliação num fim em si mesma: dizer que se efectuou a avaliação, convertê-la num trâmite ou num motivo de auto-satisfação ou auto-complacência." Ora este (ab)usar da avaliação tanto pode ocorrer por parte das escolas que realizam a auto-avaliação, como por parte da administração educacional que promove a avaliação externa. 0 mesmo se pode dizer em relação ao "perigo" de "Esperar que a avaliação por si mesma resolva os problemas ou elimine as dificuldades."11 (SANTOS GUERRA, 2002, p. 287-288). A utilização da avaliação com fins meramente laudatórios ou de simples (re)legitimação do sistema tem sido frequentemente denunciada e está já razoavelmente documentada na investigação.

0 contexto macro estrutural em que a pressão para a avaliação se vem desenvolvendo constitui, como referimos acima, outro dos factores fortemente condicionantes da sua subordinação ora a um "topos emancipatório", ora a um "topos regulatório". ${ }^{2}$ Ball (2002, p. 4)), depois de argumentar que, nos tempos actuais, a reforma da educação alastra como um epidemia, considera que "os elementos chave do 'pacote' da reforma da educação- e isto aplica-se com igual vigor e importância a escolas, colégios e univer-

\footnotetext{
${ }^{10}$ Não se trata, portanto, de defender que o olhar externo é mais objetivo do que o olhar interno, mas antes de defender a validação intersubjectiva dos olhares.

11 É oportuno lembrar aqui o que afirmou um alto responsável da IGE num encontro internacional em Lisboa, no início de Dezembro de 2007. Nesse encontro, em que participaram inspetores de vários paises europeus, o citado alto responsável da IGE, convocando o Secretário Geral da Associação Britânica dos Diretores das Escolas e dos Colégios, fez-nos saber que "do mesmo modo que não é por pesar o porco mais vezes que este engorda, também não há evidência de que mais inspeção melhore as escolas."

${ }^{12}$ Expressões que tomamos aqui de Estêvão (2001, p. 159).
} 
sidade- são o mercado, a capacidade de gestão e a performatividade". Esclarece depois o mesmo autor ${ }^{13}$ que a " performatividade é uma tecnologia política, uma cultura e um modo de regulação que se serve de críticas, comparações e exposições como meios de controlo, atrito e mudança." Ball ${ }^{14}$ alerta para os vários riscos que os "terrores da performatividade" podem representar para a "natureza da alma do professor", denunciando as várias "fabricações" que inevitavelmente induz. Neste contexto, a "gestão da impressão" parece sobrepor-se às relações baseadas na autenticidade. A este propósito Ball (2002, p. 12) afirma: "O que é produzido é um espectáculo, ou o que poderíamos considerar uma 'fantasia encenada' (BUTLER, 1990), que está lá apenas para ser vista e julgada." Mais adiante este autor reitera esta análise ao afirmar: "Algumas instituições educacionais tornar-se-ão no que for necessário tornar-se para florescer no mercado. Para elas, o coração do projecto educacional é aberto e esvaziado. A autenticidade corre o risco de ser inteiramente substituida pela plasticidade." (BALL, 2002, p. 16).

Um dos efeitos mais aparentemente contraditórios desta "esquizofrenia performativa" e deste "surto de avaliacionite" (ESTÊVÃO, 2001), é que a obsessão pela qualidade possa ter diversos "efeitos perversos", resultando mesmo numa qualidade desqualificada. Estêvão (2001, p. 172), num texto onde discute algumas das ambiguidades das políticas educativas portuguesas no período compreendido entre a segunda metade da década de 90 do séc XX e início do séc XXI, trecho temporal correspondente a uma fase de governação socialista, apresenta como uma das conclusões da sua análise a possibilidade de "a importância crescente concedida quer à autonomia quer à avaliação (e também ao novo papel da Inspecção) poder, contraditoriamente, reduzir a qualidade da educação em nome da qual foram promulgadas." Efectivamente, os "custos", directos e indirectos, inerentes aos processos de promoção da qualidade e da excelência, podem comprometer seriamente a consecução daqueles objectivos. Shore e Wright (1999, p. 570 apud BALL, 2002, p. 16), consideram que: "Para ser alvo de uma auditoria, uma organização tem de se tornar a si própria, activamente, numa organização auditável". Contudo, a aquisição de "informação performativa" pode envolver custos tão elevados que exaure os recursos necessários à promoção de uma oferta educativa de qualidade. Como afirma Elliot (1996, p. 15 apud BALL, 2002, p. 12), a obtenção daquela informação "consome tanta energia, que reduz drasticamente a energia disponivel para se fazerem melhoramentos para se evoluir".

Por outro lado, a importância que a "gestão da impressão" assume no "novo mundo das organizações performativas" (BALL, 2002, p. 9) pode igualmente deslocar para a "operações de cosmética" (ESTÊVÃO, 2001) verbas que, de outro modo, poderiam ser aplicadas no enriquecimento das ofertas educativas. De facto, como

\footnotetext{
${ }^{13}$ Ball $(2002$, p. 6) esclarece que: "As tecnologias políticas envolvem a distribuição calculada de técnicas e artefatos para organizar forças e capacidades humanas em redes operacionais e funcionais de poder."

${ }^{14}$ Esclarece Ball (2002, p. 15) que as "fabricações que as organizações (e indivíduos) produzem são seleções entre várias representações ou projeções possiveis - ou versões da organização ou da pessoa. [...] As fabricações são versões de uma organização (ou pessoa) que não existe - não estão "fora da verdade" mas também não transmitem simplesmente explicações diretas e verdadeiras - elas são produzidas propositadamente para "serem explicáveis".
} 
defendemos noutro texto (SÁ, 2004, p. 313), um dos grandes receios decorrentes da introdução da competição entre escolas, e da sua demanda da qualidade, é que estas desviem para a promoção da sua imagem pública verbas que noutro cenário poderiam ser investidas na criação de oportunidades de formação mais ricas. Vários autores (BALL, 1993; GEWITZ et al, 1995; RAAB et al., 1997; WHITTY; POWER, 1997) têm alertado para este efeito perverso da competição, com uma parte substancial dos recursos sendo canalizados para o marketing, em detrimento das actividades educativas. A panóplia de recursos de que as escolas se podem socorrer para fabricar a sua imagem perante públicos relevantes pode ser muito diversificada:

Certamente que as escolas se tornaram muito mais atentas e conscientes da 'necessidade' de organizar cuidadosamente as formas através das quais se 'apresentam' aos pais actuais ou potenciais, usando publicações promocionais, eventos escolares, 'produções' escolares, noites abertas, semanas abertas, páginas de Internet e a cobertura de acontecimentos pela imprensa local. (BALL, 2002. p. 17).

Outra das implicações da "obsessão performativa" e da "qualidade como critério mercantil" (GENTILI, 1997), será a de valorizar apenas o que é mensurável e evitar tudo aquilo que possa pesar negativamente naquela medição. Assim, por exemplo, quando a qualidade é medida em termos de resultados escolares, e estes são aferidos a partir dos desempenhos nos exames nacionais, as escolas serão induzidas a concentrarem-se na preparação dos alunos para que estes sejam bem sucedidos nesses momentos de (in)verdade. Este teach to the test (BALL, 1993, p. 107), induzirá, entre outras consequências, a secundarização das aprendizagens mais dificilmente mensuráveis como, por exemplo, a educação para a democracia e para a participação, o desenvolvimento do espírito crítico, desenvolvimento global da personalidade. ${ }^{15} \mathrm{Na}$ verdade, os exames, além de efectuarem uma "usurpação do currículo", como afirma Dias Sobrinho (2000, p. 97), "acabam lançando uma visão embaçada sobre o ensino e a aprendizagem e empobrecem os objectivos curriculares a fim de poderem medi-los", desta forma contribuindo para mais uma das muitas formas de desqualificação da qualidade que supostamente perseguem. ${ }^{16}$

Por outro lado, num contexto marcado pela "interdependência competitiva" (VAN ZANTEN, 2006), e considerando que a qualidade do produto final depende também da possibilidade de se seleccionarem as melhores matérias-primas, as escolas poderão sentir-se tentadas, senão mesmo obrigadas, a seleccionar criteriosamente as suas entradas, dessa forma produzindo diferentes formas de exclusão. É para este "efeito colateral" das pressões avaliativas que gostaríamos de orientar agora o nosso foco de análise.

\footnotetext{
${ }^{15}$ Michael Apple (2001, p. 17), numa entrevista concedida a Michael Shaughnessy, Kathy Peca e Janna Siegel, assumindo uma frontal denúncia do que vem denominando de "individualismo possessivo", afirmou: "Atualmente, debaixo da influência do neoliberalismo, o verdadeiro significado da cidadania foi radicalmente transformado. Nos dias de hoje o cidadão é um simples consumidor. 0 mundo é visto como um vasto supermercado."

${ }^{16} \mathrm{~A}$ insensibilidade à "dispersão semântica" do termo qualidade (MANILA, 1989, p. 24 apud DIAS SOBRINHO, 2000, p. 105) tem facilitado a sua instrumentalização ao serviço de agendas muito diversas.
} 


\section{Avaliação, excelência e "efeitos colaterais"}

A literatura sobre as escolas eficazes é hoje bastante abundante e diversificada. Nas várias análises, os factores de sucesso, apesar de não serem completamente sobreponiveis, tendem a apresentar alguma convergência. De entre esses factores salientam-se a liderança forte e orientada para as metas educacionais, visão e objectivos claros e partilhados, corpo profissional coeso e dedicado, expectativas elevadas e suportadas por estratégias de apoio e reforço positivo, salas de aula mais organizadas e disciplinadas, relação de colaboração e parceria entre a escola e a família. Há, no entanto, uma característica comum às escolas de sucesso que raramente é sinalizada: elas beneficiam, por razões diversas, de um público onde se verifica uma clara sobre-representação dos grupos socialmente favorecidos. Ainda que nem sempre o verbalizem, as escolas têm uma consciência aguda da relevância deste pré-requisito como condição para o sucesso. Por isso, a procura selectiva de clientes constitui uma prática que a literatura especializada desde há muito vem documentando. Raab e outros (1997), por exemplo, num estudo que conduziram em três autoridades educativas locais (distritos escolares) inglesas e escocesas, nas quais seleccionaram doze escolas com características diversas, concluíram que essas escolas não estavam apenas preocupadas com o número de alunos mas também em atrair os alunos certos. Como notam estes autores, tomando por referência o estudo que realizaram, "nas três áreas estudadas, as escolas que procuravam aumentar o número de alunos, queriam estudantes que pudessem incrementar a reputação da escola e a sua posição na liga dos desempenhos: em sintese, crianças da classe média" (RAAB et al., 1997, p. 147). Também Whitty e Power (1997, p. 226), agora tomando como objecto de estudo os efeitos das reformas educativas durante os governos de Thatcher e Major (anos oitenta e noventa), com destaque para os casos de Inglaterra e País de Gales, e tomando também como referência estudos anteriores, reforçam esta mesma conclusão ao afirmarem que

[...] a clientela menos desejável inclui os que são 'menos capazes, têm necessidades educativas especiais, especialmente dificuldades emocionais e comportamentais, bem como crianças oriundas da classe operária e rapazes, a menos que eles tivessem também alguns dos atributos desejáveis. ${ }^{17}$

Ball (2005) alerta também para a "mercantilização do aluno" decorrente das pressões competitivas e da necessidade de bons desempenhos nas "Tabelas de Avaliação". A este propósito este autor afirma:

Com efeito, as escolas entram em competição para recrutar os alunos mais aptos a contribuir para o 'aperfeiçoamento'

\footnotetext{
${ }^{17}$ Segundo Whitty e Power (1997, p. 227 ) é fácil compreender porque é que as escolas estão particularmente interessadas em atrair os alunos academicamente mais aptos: "Estes estudantes permanecem no sistema mais tempo e assim trazem para a escola mais dinheiro, além de a fazerem parecer mais bem sucedida em termos de scores nos testes e, por isso, atrativa para outros clientes desejáveis."
} 
e para o 'desempenho', mais fáceis e mais baratos de ensinar e mais capazes de contribuir para atrair outros alunos como eles. [...] Nesta economia, algumas crianças têm um valor elevado, ou seja, 'acrescentam valor' e são muito procuradas; outras, porém, têm baixo valor, isto é, 'acrescentam valor negativo.' (BALL, 2005, p. 15).

Num contexto marcado por fortes induções competitivas, onde as escolas são pressionadas a mostrar resultados ${ }^{18}$, os alunos são reduzidos à sua condição de alunos-mercadoria..$^{19}$ No caso português, a interconexão de um conjunto diversificado de recentes medidas de política educativa, onde se incluem a obrigatoriedade de avaliação das escolas (Lei n ${ }^{\circ} 31 / 2002$, de 20 de dezembro) ${ }^{20}$, o novo estatuto da carreira dos docentes do ensino não superior (Decreto-Lei n ${ }^{\circ}$ 15/2007, de 19 de janeiro ${ }^{21}$ e consequente definição de um novo sistema de avaliação do desempenho do pessoal docente da educação pré-escolar e dos ensinos básico e secundário (Decreto Regulamentar no 2/2008, de 10 de janeiro) ${ }^{22}$, a celebração dos primeiros "contratos de autonomia" 23 e a aprovação do novo "regime de autonomia, administração e gestão dos estabelecimentos da educação pré-escolar e dos ensinos básico e secundário" (Dec. Lei n ${ }^{\circ}$ 75/2008, de 22 de abril) ${ }^{24}$, pode ser indutora, não apenas de "rivalidade interinstitucional" (LIMA; AZEVEDO; CATANI, 2008), mas militar também no sentido de gerar excluídos. Apesar de todos os normativos acima referidos conferirem uma grande importância à avaliação e de se auto-justificarem invocando a agenda da qualidade e da excelência, começam a ser sinalizados alguns indícios que apontam para os "efeitos colaterais" antes enunciados. Desde logo, a indexação das competências a transferir para as escolas, no âmbito da celebração dos "contratos de autonomia", aos resultados da avaliação externa ${ }^{25}$, pode constituir um forte

\footnotetext{
${ }^{18}$ Como afirma ainda Ball $(2005$, p. 21): "Escolhemos e avaliamos as nossas ações cada vez mais em termos de eficácia e de aparência. As convicções e os valores já não são importantes - é o resultado que conta. As convicções e os valores fazem parte de um discurso do serviço público obsoleto e cada vez mais deslocado."

${ }^{19}$ Importa realçar que, dentro desta lógica competitiva, a mais valia de um aluno não depende apenas do seu potencial acadêmico. 0 seu capital social e financeiro é igualmente importante. Num contexto de retração dos investimentos públicos na educação as escolas dependerão cada vez mais da sua capacidade de obter formas de financiamento suplementar, nomeadamente para proporcionarem atividades extracurriculares. Assim, as familias de mais recursos serão naturalmente as que melhor se ajustam aos requisitos da nova ordem.

${ }^{20}$ Ver Portugal (2002, p. 7952-7954).

${ }^{21}$ Ver Portugal (2007, p. 501-547).

${ }^{22}$ Ver Portugal (2008 b, p. 225-233).

${ }^{23}$ Apesar de previstos desde 1998 (Dec. Lei no 115-A/98), os "contratos de autonomia" só muito recentemente começaram a ser assinados e, neste momento, ainda apenas com um número muito reduzido de escolas. De acordo com o normativo acima referido, "Por contrato de autonomia entende-se o acordo celebrado entre a escola, o Ministério da Educação, a administração municipal e, eventualmente, outros parceiros interessados, através do qual se definem os objetivos e se fixam as condições que viabilizam o desenvolvimento do projeto educativo apresentado pelos órgãos de administração e gestão de uma escola ou de um agrupamento de escolas. "(ponto 1 do art $^{\circ} 48^{\circ}$ ). A celebração dos "contratos de autonomia" pressupõe o cumprimento de três requisitos prévios: "a) Adoção por parte da escola de dispositivos e práticas de auto-avaliação; b) Avaliação externa no âmbito do Programa de Avaliação Externa das Escolas [levada a cabo pela Inspeção Geral da Educação]; c) Aprovação pela assembleia de escola e validação pela respectiva direção regional de educação de um plano de desenvolvimento da autonomia que visa melhorar o serviço público de educação, potenciar os recursos educativos da unidade de gestão e ultrapassar as suas debilidades, de forma sustentada."(Portaria $n^{\circ}$ 1260/2007, art $\left.{ }^{\circ} 3^{\circ}\right)$.

${ }^{24}$ Ver Portuga I (2008 a, p. $\left.2341-2356\right)$.

${ }^{25}$ No preâmbulo do Decreto -Lei no 75/2008 (PORTUGAL, 2008a), afirma-se com toda a clareza que: "A associação entre a transferência de competência e a avaliação externa da escola para o seu exercicio constitui um princípio fundamental."
} 
fator indutor daqueles "efeitos colaterais". Por exemplo, há não muito tempo, chegou-nos o eco de uma "denúncia informal" relativamente a um agrupamento de escolas que, na sequência da assinatura de um "contrato de autonomia", no âmbito do qual assumiu o compromisso em relação ao alcance de certas metas em termos de resultados escolares, estaria a pôr obstáculos à admissão de alunos com necessidades educativas especiais. A singularidade (e "originalidade") deste caso, segundo a versão que chegou até nós, estaria no invocar do interesse das crianças excluidas para justificar a sua exclusão. ${ }^{26}$

A importância do ficar bem na fotografia da avaliação externa não tem apenas implicações sobre o nível de autonomia de que a escola pode usufruir. De acordo com o recente normativo da avaliação do desempenho docente (PORTUGAL, 2008b), a classificação dos professores contempla as seguintes menções qualitativas: Excelente, Muito Bom, Bom, Regular e Insuficiente. A menção de Bom constitui a classificação mínima necessária para uma progressão normal. As menções de Excelente e Muito Bom, entre outras vantagens, conferem o direito a bonificações na progressão na carreira. Contudo, a atribuição das menções de Excelente e Muito Bom está sujeita a contingentação, traduzida na fixação de percentagens máximas para aquelas classificações. Ora, a definição daquelas percentagens máximas, por escola, decorre de "despacho conjunto dos membros do Governo responsáveis pelas áreas da educação e da Administração Pública, as quais terão obrigatoriamente por referência os resultados obtidos na respectiva avaliação externa"27 (ponto 4 , art ${ }^{\circ} 1^{\circ}$ ). Também por esta razão as escolas podem sentir-se tentadas a cuidar da "safra" 28 para não terem que responder por "colheitas" menos generosas. ${ }^{29}$

As interconexões entre o novo estatuto da carreira docente e os resultados da avaliação externa podem ainda apresentar "consequências" a outros níveis. Uma das principais (e mais contestadas) alterações introduzidas pelo estatuto da carreira dos docentes do ensino não superior (PORTUGAL, 2007) consistiu na segmentação da-

\footnotetext{
${ }^{26}$ De acordo com a versão que nos relataram, a "estratégia" envolvia (envolve?) o seguinte procedimento: o órgão de gestão, quando tomava conhecimento que os pais de determinada criança com necessidades educativas especiais desejavam matricular o seu educando naquela escola, chamava os pais à escola para lhes expressar a sua solidariedade na luta por uma educação de qualidade para os respectivos educandos, aproveitando a oportunidade para os informar que, lamentavelmente, naquele momento aquela escola ainda não tinha as condições ideais para dispensar a educação de qualidade que aqueles pais tinham o direito de exigir para os seus filhos, sugerindo-lhes de seguida algumas "alternativas".

${ }^{27}$ Ver Portugal (2008b, grifo nosso).

${ }^{28}$ No ranking das escolas secundárias portuguesas organizado com base nos resultados dos exames do $12^{\circ}$ ano, e publicado pelo diário 0 Público em 21 de Outubro de 2006, verificou-se que uma escola da região central do país sofreu uma surpreendente queda de cerca de 400 lugares em relação ao ranking do ano anterior (passou da posição $152 \mathrm{em} 2005$ para a posição $549 \mathrm{em}$ 2006, ou seja, quase a última da tabela ). Confrontada esta brusca e acentuada perda de "qualidade", uma dirigente da escola justificou esta ocorrência nos seguintes termos: "Como costumamos dizer, a safra este ano não foi muito boa", acrescentando de seguida, "atendendo a que o corpo docente é o mesmo, que demos aulas de apoio, que temos salas de estudo, podemos dizer que era um grupo fraco." (Cf. Público de 21 de Outubro de 2006 - suplemento, p. 3).

${ }^{29} \mathrm{O}$ novo sistema de avaliação de desempenho docente, ao incluir na avaliação de cada docente, na componente dos objetivos individuais, a respectiva contribuição para a "melhoria dos resultados escolares dos alunos" e para a "redução do abandono escolar", pode igualmente ser indutor de "procura seletiva de públicos", seja por parte da escola, seja por parte de cada docente individualmente considerado. Neste contexto, a distribuição do serviço docente ganha uma nova centralidade pois ficar com as turmas "certas" pode ser o caminho mais curto e menos "dispendioso" para ser bem classificado nos dois parâmetros referidos.
} 
quela carreira em duas categorias: professor e professor titular. ${ }^{30} 0$ acesso à categoria de professor titular, além de um conjunto amplo de exigências (desde logo o requisito de ter pelo menos 18 anos de serviço e ser aprovado em prova pública realizada para esse efeito), está também dependente da existência de vaga. Em termos globais, como se determina no normativo supra-citado (PORTUGAL, 2007): "A dotação dos lugares da categoria de professor titular corresponde, por quadro de agrupamento ou de escola não agrupada, a um terço do número total de lugares do respectivo quadro" (ponto 3, art ${ }^{\circ} 26^{\circ}$ ). Contudo, o número de lugares de professores titulares a prover não pode ultrapassar a dotação anualmente fixada pelo Governo e esta dotação, como se esclarece no $\operatorname{art}^{\circ} 38^{\circ}$, ponto 4, do mesmo normativo, será fixada "ponderados os resultados da avaliação externa do estabelecimento escolar".

Mais uma vez são os "resultados da avaliação externa" que contam, e esta apenas conta se for realizada pelos serviços do Ministério da Educação e mais especificamente pela Inspecção Geral de Educação. Apesar de existirem em Portugal outras instituições independentes que realizam avaliação externa das escolas ${ }^{31}$, os resultados dessas avaliações nada pesam no momento de definir "consequências". Tratase, também no ensino não superior, do processo de "administrativização" da avaliação que Lima, Azevedo e Catani (2008, p. 19) denunciam em relação à educação superior $^{32}$, e que reflecte a crença positivista na maior objectividade e imparcialidade dos avaliadores externos oficiais. ${ }^{33}$

\section{A concluir}

A instituição de sistemas de avaliação das escolas, em diferentes geografias sóciopolíticas, surge habitualmente associada à preocupação em promover a qualidade dos respectivos sistemas educativos. ${ }^{34}$ Contudo, a qualidade, dada a sua "dispersão semântica", pode ser invocada ao serviço de agendas e agentes muito diversos. De resto, frequentemente, a qualidade desdobra-se em valores que, apesar da sua forte consensualidade e aparente convergência, raramente podem ser satisfeitos em simultâneo. Assim, por exem-

\footnotetext{
${ }^{30}$ De acordo cm o novo Estatuto da Carreira Docente do Ensino não Superior (PORTUGAL, 2007): "a carreira docente passará a estar estruturada em duas categorias, ficando reservado à categoria superior, de professor titular, o exercício de funções de coordenação e supervisão. Para acesso a esta categoria, estabelece-se a exigência de uma prova pública que, incidindo sobre a atividade profissional desenvolvida, permita demonstrar a aptidão dos docentes para o exercício das funções específicas que Ihe estão associadas"(preâmbulo). Além das funções de coordenação e supervisão, o professor titular desempenha também funções de avaliação dos outros docentes.

${ }^{31}$ Em Portugal, entre outras instituições independente que levam a cabo avaliação externa de escolas, destaca-se a Fundação Manuel Leão. Esta instituição, criada em 1996, é responsável pelo Programa AVES - Avaliação de Escolas Secundárias - e vem desenvolvendo o seu trabalho desde o ano de 2000. No desenvolvimento do seu trabalho no domínio da avaliação das escolas, a Fundação Manuel Leão tem contado com o apoio financeiro da Fundação Calouste Gulbenkian.

${ }^{32}$ Lima, Azevedo e Catani (2008, p. 19) consideram que esta "administrativização" da avaliação vem sendo induzida pela Nova Gestão Política. Acrescentam ainda os mesmos autores, na linha de Rosanvallon (2006), que a "sociedade da auditoria, ou da notação "associada à "administrativização" da avaliação, nos conduz para uma "democracia da desconfiança organizada".

${ }^{33}$ Afirmam Lima, Azevedo e Catani (2008, p. 19) que "a avaliação positivista e tecnocrática", ao basear-se "numa espécie de realismo ingênuo, remete para uma ontologia da exterioridade, na qual a realidade é independente da consciência dos atores."

${ }^{34}$ No caso do sistema educativo português, o normativo que aprova o sistema de avaliação da educação e do ensino não superior inclui nos seus objetivos "Promover a qualidade do sistema educativo, da sua organização e dos seus níveis de eficiência, apoiar a formulação e o desenvolvimento de políticas de educação e formação e assegurar a disponibilidade de informação de gestão daquele sistema "(Lei $n^{\circ} 31 / 2002$, de 20 de Dezembro, alínea a) do art ${ }^{\circ}{ }^{\circ}$ ).
} 
plo, como advertem Sergionvanni e outros $(1987$, p. 7), citados por Natércio Afonso (2002, p. 53), valores como equidade, excelência, eficiência e liberdade, podendo ser tomados como as quatro faces de um sistema de qualidade, convivem, contudo, "num constante estado de tensão, de tal modo que uma excessiva ênfase num deles prejudica a expressão de cada um dos outros três." Também aqui se afirma a natureza política da avaliação: a prevalência de uma das faces sobre as outras depende, em última instância, do (des)equilibrio) de poderes dos agentes e das agendas em presença.

Paralelamente, em Portugal raramente se tem equacionado a avaliação da escola enquanto "organização educativa complexa" (AFONSO, A. J., 2003), privilegiando-se antes formas pobres e "preguiçosas" de avaliação (AZEVEDO, 2007), com destaque para a produção e divulgação dos muito propagandeados rankings das escolas, sub-produto da média aritmética dos resultados dos exames do $12^{\circ}$ ano. Os efeitos de "beatificação" das escolas melhor posicionadas (e consequente branqueamento de alguns dos processos que as catapultaram a essa posição) e de "demonização" das relegadas para o fim da tabela (e consequente apagamento dos esforços e implicação dos que ai trabalham) são hoje já relativamente bem conhecidos.

Uma visão acrítica e ingénua, ainda que bem intencionada, dos processos de avaliação das escolas leva com frequência a um registo normativo e laudatório que põe em destaque as "virtudes" e as potenciais "melhorias" associadas àqueles processos. Contudo, importa acautelar que certas formas de avaliação, sobretudo aquelas que desprezam (ou ignoram) o estatuto da escola como "organização educativa complexa", comportam também "efeitos colaterais" que podem não ser despiciendos e induzir mesmo formas de "democratização segregativa" (MERLE, 2002). Estes riscos surgem fortemente potenciados em contextos de pressões performativas e quando se indexa, como no caso português, aos resultados da avaliação um conjunto de "prémios e castigos". Nestas circunstâncias, como assinala Ball (2002, p. 16): "as fabricações organizacionais são uma fuga ao olhar atento e directo, uma estratégia de gestão da impressão que, de facto, cria uma fachada calculada"35.

Neste contexto, o professor tenderá cada vez menos a trabalhar com as crianças, para a passar a trabalhar as crianças para que estas brilhem nos testes. As escolas, naturalmente, envolver-se-ão cada vez menos nos absorventes e exigentes processos de promoção do sucesso educativo, para se dedicarem a vistosas encenações de fabricação dos resultados. Aqui, mais importante do que a autenticidade, parece ser a plasticidade, ou seja, a capacidade de ajustamento às demandas do momento, o que implica, desde logo, "reformar" o próprio professor. É que, como alerta Ball (2002, p. 3): "A reforma não muda apenas o que nós fazemos, muda também quem somos".

Apesar das dificuldades e limites que a assunção da escola como "organização educativa complexa" coloca aos processos avaliativos, e muito particularmente à avaliação

\footnotetext{
${ }^{35}$ Acrescenta o mesmo autor (BALL, 2002, p. 19) que: "As tecnologias políticas do mercado, gestão e performatividade não deixam espaço para um ser ético autônomo ou coletivo. Estas tecnologias politicas têm potencialmente profundas consequências para a natureza do ensinar e do aprender."
} 
do "factor-escola", como oportunamente adverte Azevedo (2007, p. 69), essas condicionantes impõem prudência, mas não justificam a desistência. 0 que se impõe é a superação da visão simplista e redutora de um processo que é, antes de mais, político (DIAS SOBRINHO, 2000), ou seja, envolve uma grande pluralidade (e conflitualidade) de interesses, valores, perspectivas, objectivos. Reconhecer o amplo "arco semântico do conceito de avaliação" (SANTOS GUERRA, 2002, p. 272), concebê-la como uma prática instituinte que corporiza uma construção colectiva que se actualiza em cada escola enquanto "arena política", constituem dois "requisitos" básicos para resgatar a avaliação institucional das derivas gerencialistas e (re)colocá-la ao serviço de uma agenda que persegue a "qualidade democrática" da escola (AFONSO, A. J., 2003).

\section{Referências}

AFONSO, A. J. Avaliar a escola e a gestão escolar: elementos para uma reflexão crítica. In: ESTEBAN, M. T. (Org.). Escola, currículo e avaliação. São Paulo: Cortez, 2003.

Políticas educativas e a avaliação educacional. Braga: CIEd: UM, 1998.

Políticas educativas e avaliação de escolas: por uma prática avaliativa menos regulatória. In: SIMPÓSIO SOBRE ORGANIZAÇÃO E GESTÃO ESCOLAR, 2., 2002, Aveiro. Actas... Aveiro: Universidade de Aveiro, 2002.

AFONSO, N. Avaliação e desenvolvimento organizacional da escola. In: SIMPÓSIO SOBRE ORGANIZAÇÃO E GESTÃO ESCOLAR, 2., 2002, Aveiro. Actas... Aveiro, PT: Universidade de Aveiro, 2002.

APPLE, M. Reestruturação educativa e curricular e as agendas neoliberal e neoconservador [entrevista conduzida por Michael Shaughnessy, Kathy Peca e Janna Siegel].

Currículo sem Fronteiras. [S. I.], v. 1, n.1, p. 5-33, jan./jun. 2001. Edição electrónica.

AZEVEDO, J. Avaliação das escolas: consensos e divergências. Porto: Edições ASA, 2002.

AZEVEDO J. M. Avaliação das escolas: fundamentar modelos e operacionalizar processos. In: SEMINẢRIO AVALIAÇÃO DAS ESCOLAS: modelos e processos, 2007, Lisboa. Actas... Lisboa: Conselho Nacional de Educação, 2007.

BALL, S. Educação à venda. Viseu: Pretexto, 2005.

Educational markets, choice and social class: the market as a class strategy in UK and the USA. British Journal of Sociology of Education, London, v. 14, n. 1, p. 3-19, 1993.

Reformar escolas, reformar professores e os terrores da performatividade. $\overline{R e v i s t a}$ Portuguesa de Educação, Braga, Vol. 14, n² 2, p. 03-23, 2002.

CANÁRIO, R.; ALVES, N.; ROLO, C. Escola e exclusão social: para uma análise crítica da política Teip. Lisboa: Educa, 2001. 
CLARKE, J.; NEWMAN, J. The managerial state: power, politics and ideology in the remaking of social welfare. London: Sage, 1997.

CNE (Portugal). Avaliação das escolas: modelos e processos. Lisboa: CNE, 2007. Actas de um Seminário realizado em 13 de dezembro de 2005.

CORREIA, J. A.; MATOS, M. Solidões e solidadriedades nos quotidianos dos professores. Porto: Edições ASA, 2001.

COSTA, J. A. Avaliação, ritualização e melhoria das escolas: à procura da roupa do rei.... In: MIGUÉNS, M. (Ed.). Avaliação das escolas: modelos e processos. Lisboa: Conselho Nacional de Educação, 2007.

COSTA, J. A.; VENTURA, A. Avaliação e desenvolvimento organizacional. Infância e Educação: investigação e práticas, Lisboa, n. 7, p. 148-161, nov. 2005.

DIAS SOBRINHO, J. Avaliação da educação superior. Petrópolis: Vozes, 2000.

Avaliação institucional: a experiência da Unicamp: condições, princípios, processo. Pró-Posições, Campinas, v. 6, n. 1, 1995.

ENGUITA, M. 0 discurso da qualidade e a qualidade do discurso. In: GENTILI, P.; SILVA, T. T. (Org.). Neoliberalismo, qualidade total e educação. Petrópolis: Vozes, 1997.

ESTÊVÃO, C. V. Políticas educativas, autonomia e avaliação. Reflexões em torno da dialéctica do reajustamento da justiça e da modernização. Revista Portuguesa de Educação, Braga, n. 2, p. 155-178, 2001.

GENTILI, P. 0 discurso da "qualidade" como nova retórica conservadora no campo educacional. In: GENTILI, P.; SILVA, T. T. (Org.). Neoliberalismo, qualidade total e educação. Petrópolis: Vozes, 1997.

GEWIRTZ, S.; BALL, S.; BOWE, R. Markets, choice and equity. Milton Keynes: Open Unversity Press, 1995.

LIMA, L. C. Avaliação e concepções organizacionais de escola: para uma hermenêutica organizacional. In: SIMPÓSIO SOBRE ORGANIZAÇÃO E GESTÃO ESCOLAR, 2., 2002, Aveiro. Actas... Aveiro: Universidade de Aveiro, 2002.

Modernização, racionalização e optimização: perspectivas neotaylorianas na organização e administração da educação. Cadernos de Ciências Sociais, Porto, n. 14, p. 119-139, jan. 1994.

O paradigma da educação contábil: políticas educativas e perspectivas gerencialistas no ensino superior em Portugal. Revista Brasileira de Educação, Campinas, SP, n. 4, p. 43-59, jan./fev./abr. 1997. 
LIMA, L. C.; AZEVEDO, M.; CATANI, A. 0 processo de Bolonha, a avaliação da educação superior e algumas considerações sobre a Universidade Nova. Avaliação, Sorocaba, SP, v. 13, n. 1, p. 7-36, 2008.

MANGUEZ, E. Régulation de l'action éducative dans les années quatre-vingt dix. Éducation et Societés, Issy-les-Moulineaux, FR, v. 8, n. 2, p. 81-96, 2001.

MERLE, P. La démocratisation de l'enseignement. Paris: La Découverte, 2002.

OCDE. As escolas e a qualidade. Rio Tinto: Edições Asa, 1992.

PORTUGAL. Lei n. 31/2002, de 20 de dezembro de 2002. Aprova o sistema de educação e do ensino não superior, desenvolvendo o regime previsto na Lei n.o 46/86, de 14 de Outubro (Lei de Bases do Sistema Educativo). Diário da República, Lisboa, 1. série - A, n. 294, p. 7952-7954, 20 dez. 2002. Disponível em: $<$ http://www.gave.min-edu.pt/np3content?newsld=31氏tfileName=lei_31_2002.pdf>. Acesso em: 24 mar. 2009.

Ministério da Educação. Decreto-Lei n 15/2007, de 19 de janeiro de 2007. No Programa do XVII Governo Constitucional reafirma-se a noção de que os educadores e professores são os agentes fundamentais da educação escolar. Diário da República, Lisboa, 1. série - A, n. 14, p. 501-547, 19 jan. 2007. Disponível em: <http://min-edu.pt/np3content/?newsld=1176\&fileName=decreto_lei_15_2007.pdf>. Acesso em: 24 mar. 2009.

PORTUGAL. Ministério da Educação. Decreto-Lei no 75/2008, de 22 de abril de 2008. As escolas são estabelecimentos aos quais está confiada uma missão de serviço público [...] Diário da República, Lisboa, 1. série, n. 79, p. 2341-2356, 22 abr. 2008a. Disponível em: <http://min-edu.pt/np3content/?newsld=1953\&fileName=decreto_lei_75_2008.pdf>. Acesso em: 24 mar. 2009.

. Decreto Regulamentar n. 2/2008, de 10 de janeiro de 2008. 0 Decreto -Lei n. ${ }^{15 / 2007}$, de 19 de Janeiro, procedeu à alteração ao Estatuto da Carreira dos Educadores de Infância e dos Professores dos Ensinos Básico e Secundário [...]Diário da República, Lisboa, 1. série, n. 7, p. 225-233, 10 jan. 2008b. Disponível em: <www.dre.pt/pdf1sdip/2008/01/00700/0022500233.PDF>. Acesso em: 24 mar. 2009.

RAAB, C. et al. Devolving the management of schools in Britain. Educational Administration Quarterly, Columbus, OH, v. 33, n. 2, p. 140-157, April 1997.

ROSANVALLON, P. La contre-démocratie: la politique à l'âge de la défiance. Paris: Seuil, 2006. 
SÁ, V. A participação dos pais na escola pública portuguesa: uma abordagem sociológica e organizacional. Braga: Universidade do Minho, 2004.

SANTOS GUERRA, M. Entre bastidores: o lado oculto da organização escolar. Porto: Edições ASA, 2002.

. Uma seta no alvo: a avaliação como aprendizagem. Porto: Edições ASA, 2003.

SERGIOVANNI, T. J. et al. Educational governance and administration. New Jersey: Prentice-Hall, 1987.

SIMÕES, G. M. J. A auto avaliacao das escolas e a regulação da acção pública em educação. Sísifo: revista de ciências da educação, Lisboa, v. 4, p. 39 48, out./dez. 2007. Disponivel em: <http://sisifo.fpce.ul>. Acesso em: 25 mar. 2009.

SOLEAUX, G. Un point de vue histórique... In: DUTERQ, Y. (Dir.). Les régulations dês politiques d'éducation. Rennes: PRU, 2005.

STUFFLEBEAM, D. Evaluation models. San Francisco: Jossey-Bass, 2001. (New Directions for Evaluation; 89).

VAN ZANTEN, A. Interdependência competitivas e as lógicas de acção das escolas: uma comparação europeia. In: BARROSO, J. (Org.). A regulação das politicas públicas de educação: espaços, dinâmicas e actores. Lisboa: Educa: UI\&DCE, 2006.

VANDENBERGHE, V. Nouvelles formes de régulation dans I'enseignement: origines, role de l'évaluation et enjeux en thermes d'équité et d'efficacit. Éducation et Societés, Issy-les-Moulineaux, FR, v. 8, n. 2, p. 111-123, 2001.

VENTURA, J. A. Avaliação e inspecção das escolas: estudo de impacte do Programa de Avaliação Integrada. 2006. 968 f. Tese (Doutorado em Ciências da Educação) - Universidade de Aveiro, Aveiro, 2006.

WHITY, G.; POWER, S. Quasi-markets and curriculum control: making sense of recent education reform in England and Wales. Educational Administration Quarterly, Columbus, OH, v. 33, n. 2, p. 219-240, April 1997.

Recebido em: 22/08/2008

Aceito para publicação em: 09/03/2009 